\title{
The dynamics of imposed transparency and its role in deep social conflicts
}

\author{
Shaul A. Duke
}

\section{Introduction}

The term "transparency" lives a double life. On the one hand, it has the cleancut image of a universal standard of proper operation in a free society, an image that seems to be accepted by most; on the other hand, however, it has the rougher image of a power move that tries to expose its target to scrutiny and undermine some of its actions. In this chapter I differentiate between the two and analyze the dynamics of the much less studied "imposed transparency" strand. In particular, I analyze how transparency is imposed as a strategy in a preexisting social conflict characterized by a low level of trust between the relevant parties from the start. In such conflict situations, when the parties do not trust each other, transparency is almost always forced by one party on the other (via surveillance) and almost never willingly adopted by either party. I am interested in: the reasons why individuals/organizations turn to imposed transparency as a political strategy, the ways imposed transparency is carried out, the degree to which these targets tend to accept imposed transparency or resist/evade it, the dynamics that mutual attempts to impose transparency create, the role that power asymmetries have in such attempts, and the effectiveness of forcing transparency in order to achieve specific goals.

In this examination, I will first analyze some of the existing writing on transparency and chart some of its weaknesses as a social change tool. Next, I will turn to differentiate between voluntary universal transparency and imposed targeted transparency, and identify three defining features on which they diverge. I will then proceed to scrutinize the dynamics of imposed transparency as it pertains to two cases (designated A and B) within the Occupied Palestinian Territories (henceforth OPT): (A) the case of the large checkpoints ("terminals") operating within the West Bank to restrict Palestinians' movement and (B) the case of Israeli NGOs operating to safeguard Palestinians' human rights. Both cases will help clarify how and why imposed transparency is deployed, the reactions that such attempts provoke, and the end result with regard to political struggles, asymmetry, colonialism, democracy, operation with impunity, and human rights standards. 


\section{The transparency concept}

The term transparency has become widespread both among scholars and laypeople around the world (Bertot et al. 2010; Bessire 2005). It is the solution suggested to a variety of social problems that usually revolve around lack of trust (e.g. Auger 2014; Jackson 2015; Kanagaretnam et al. 2010; Rawlins 2008; Schnackenberg and Tomlinson 2016). Transparency's popularity seems to echo a human fascination with "seeing through" opaque things, yet traversing from this alluring/aesthetic notion of transparency to its actual application in complex human reality is not an easy process, and indeed transparency as a solution to social problems has been found to be very problematic in a variety of fields (Bac 2001; Bannister and Connolly 2001; Bauhr and Grimes 2014; Bessire 2005; Brucato 2015; Drucker and Gumpert 2007; Grimmelikhuijsen 2010; Grimmelikhuijsen et al. 2013; Kolstad and Wiig 2009; O'Neill 2002; Schnorf et al. 2014).

Most of the scholastic attention to the concept of transparency is focused on its relation to trust and the building/sustaining of trust. What many studies on the relations between transparency and trust suggest is that, in a variety of settings, transparency does not increase trust and sometimes actually reduces it (Allen 2008; Grimmelikhuijsen 2010; Grimmelikhuijsen et al. 2013; Margetts 2011). Yet this research thread still assumes that trust is a desired social good of its own. But as pointed out by O'Neill, this is not necessarily the case; while we should trust some individuals/organizations on some issues, we should be highly skeptical toward others (O’Neill 2002). Moreover, when referring to nontrust positive effects of transparency (e.g. fighting corruption), there are scholars who point out that if the public does not have the willingness and the means to force social change, transparency in itself is ineffective (Kolstad and Wiig 2009; Lindstedt and Naurin 2010; Marsh 2011).

Feminist surveillance literature, for its part, places a strong emphasis on the differential ways in which making things transparent affects different people (Abu-Laban 2014; Dubrofsky and Magnet 2015; Hall 2017). Transparency technologies/practices that might be considered positive or neutral may be detrimental to certain groups, such as the way full-body scanners can be disturbing for transgender or disabled people, as well as for individuals from certain religions. Nevertheless, transparency still carries a positive connotation in our society and is still widely used.

\section{Two types of transparency}

Transparency can be categorized as either imposed or adopted. Imposing transparency on a person/organization usually entails some sort of surveillance (Brucato 2015); it requires monitoring the target to achieve disclosure that is not voluntary - monitoring to which the target has not agreed (e.g. public space CCTV). In these cases, transparency is dictated by others, and consent is neither sought nor received. Indeed, some scholars call this type of 
imposed transparency "weaponized visibility" (e.g. Trottier et al. 2020; Young 2020). In our current social reality, some of these one-directional demands for transparency can be resisted, but many cannot.

The second category of transparency is that which people/organizations adopt willingly. Once a disclosure process is initiated, its adopters may be subject to new types of monitoring that can easily be perceived as surveillance. Workers who sign a consent form allowing their own electronic communications to be monitored are one such example of opening the door to their own surveillance. Not in every instance will such surveillance actually take place, but the potential is clearly there. We should note that consensual adoption of transparency does not necessarily mean it is adopted willingly. Demands to adopt transparency often involve a great degree of pressure, offering individuals or organizations deals they cannot realistically refuse. Indeed, the question of willingness to adopt transparency is tricky when transparency can expose one to scrutiny, criticism, and attack (Rawlins 2008). Once our words and/or actions become public record they can easily be misunderstood, misrepresented, or decontextualized (Bannister and Connolly 2011).

One way to mitigate some of the risks of disclosure is if the individual/ organization that was made to be transparent controls the disclosed information. For instance, with regard to substance abuse monitoring, a worker may be asked to periodically sign a declaration as opposed to being subjected to urine testing. While in the former instance the individual controls the disclosure process, which allows her/him room to maneuver (e.g. by omitting information), in the latter it does not. This control in turn may reduce the risks resulting from exposure that transparency entails and may also create a mode of good faith between the disclosing and the disclosed parties. What is especially important in understanding the legitimacy of transparency is to know toward whom the transparency procedure is applied; that is, if it is applied universally or if it is targeted. When transparency is applied evenly to all, it is much more palatable. Being asked to start swiping your employee card when entering/exiting work may seem arbitrary if it only applies to some workers. Thus, universal application is another necessary element for voluntary transparency.

Conceptually, we are left with two archetypes of transparency: voluntary transparency and imposed transparency (see Table 4.1). While they both

Table 4.I Two archetypes of transparency

\begin{tabular}{lll}
\hline & Voluntary & Imposed \\
\hline Consent & Sought & Not sought \\
Disclosure & Self-disclosure & Outside monitoring \\
Application & Universal & Targeted \\
\hline
\end{tabular}


expose an individual/group/organization to scrutiny and criticism, one is adopted willingly on the basis of some sort of social agreement and trust, while the other is imposed in a unidirectional fashion, does not rely on its targets for disclosure, and may be applied selectively according to the interest of the imposing party. The fact that both are considered "transparency" seems to benefit those practicing imposed transparency, since it attaches the positive connotations of the voluntary transparency term to what they actually do, which is almost identical to surveillance. Last, it should be noted that these are two archetypes of transparency and that actual cases of transparency may shift from one category to another or be hybrid cases.

\section{The dynamics of imposed transparency}

Imposed transparency tends to appear in situations in which there is an existing conflict and low levels of trust between the parties. Given that transparency can expose one to criticism/attacks, in conflict situations voluntarism is low and self-disclosure is regarded as highly unreliable. In such settings, forcing transparency on the other side may be a powerful strategy to achieve a desired outcome that is at odds with the other party's wishes. In cases like these, transparency is used in a utilitarian and targeted way. For instance, in certain settings transparency may be forced on a political rival or a business competitor in order to weaken them and undermine their goals (Sperling 2011). As will be shown in the empirical section, this process of enlisting transparency for a strategic goal may be undertaken by a group/organization that may be committed to transparency (as a social value) but also may not.

Moreover, imposed transparency may be initiated not only by strong groups or organizations but also by weak ones (Koskela 2012; Mann 2013; Wilson 2012; Wilson and Serisier 2010). This may seem counterintuitive since unidirectional power moves are usually associated with powerful social forces, yet marginalized groups and the advocacy organizations that represent them may also enlist certain resources (such as the courts) in order to force transparency on the powerful. For example, a weak community may impose transparency on a wealthy chemical plant in order to disclose the suspected dumping of known pollutants.

It is precisely because imposed transparency may be the weapon of the weak as well as the strong that we can talk of the phenomenon of "cycles of imposed transparency"- that is, a dynamic in which two sides increasingly use transparency in order to combat each other. Imposed transparency, as it so closely relates to surveillance, adheres to surveillance's overall pattern of move and countermove (Wilson 2012; Wilson and Serisier 2010), of being contingent upon the actions of other players. In a dynamic where several players are influencing each other, an account must be given of how each move influences the subsequent one in a sequential fashion. Accepting the forced transparency is not the only possible reaction, and the targeted party 
may resist or evade transparency. Thus, while a nontrivial part of the surveillance studies literature follows Foucault's (1991) panopticon reasoning and would expect these targeted parties to accept and internalize the imposed transparency, another part of the surveillance literature suggests resistance is the norm (e.g. Gilliom and Monahan 2012; Marx 2003). We thus might encounter a dynamic in which the panoptic gaze is not accepted but defied.

I will examine imposed transparency by focusing on the dynamics that emerge from the historical sequence that revolves around the restriction of Palestinian movement in the OPT and the defense of their human rights. My study is based on a qualitative analysis of both primary and secondary data, website content, reports and documents, and ten semi-structured interviews and correspondences with NGO activists/personnel working in the field of Palestinian human rights, some of whom have firsthand experience with new hi-tech terminals operating in the West Bank.

\section{Imposed transparency in the OPT}

Imposed transparency is at the heart of what has been occurring in the OPT since the beginning of the 2000 s, and to a lesser degree since these territories were occupied in 1967. In line with what scholars who link surveillance with colonialism have found in other places/times (e.g. Monaghan 2013; Zureik 2011), contemporary OPT is also a locus for intense implementation of surveillance technologies on indigenous people. Israeli government agencies implement a deep-reaching surveillance of Palestinian movement and actions that is pervasive and affects virtually every Palestinian (Handel 2011; Handel and Dayan 2017; Lentin 2017; Zureik 2001, 2011, 2016). They frame transparency as being carried out in the name of security considerations. The high price that ordinary Palestinians have to pay in order to provide assurance that they do not pose a threat is framed as the collateral damage of past Palestinian terrorist acts, and thus as legitimate. Although this justification of the pervasive practice of surveillance is somewhat contested, the overwhelming majority of Jews in Israel agree with it and endorse it (Avni 2006; Kuntsman and Stein 2015).

This process of forced transparency, coupled with other processes that pertain to maintaining the military occupation of the West Bank and Gaza, entails the violation of Palestinians' human rights on a large scale. These consistent violations, in turn, have provoked the emergence of several dozen advocacy groups and NGOs, some Palestinian, some Israeli, and some international, focused on stopping the violations. These advocacy groups conduct "empowering surveillance" against Israeli government agencies (Duke 2019) and impose transparency on them in turn. Since they impose transparency for policies that are seen as legitimate by most of the Jewish population, these NGOs themselves come under attack, and the Israeli NGOs in particular are subject to imposed transparency from the state. 
It is clear that trust between the parties is absent from the outset, and that it is not likely that these steps of forced transparency will produce trust. Instead, transparency is imposed in case A to produce security and control of movement, which are necessary to deepen and perpetuate the occupation, and in case B to protect Palestinian human rights and help end the occupation. This case study will be analyzed by examining the dynamics of the two sets of transparency cycles as a series of moves and countermoves.

\section{Case study A: the dynamics around checkpoints in the West Bank}

\section{First move: deploying the checkpoints}

In the early 2000s, and specifically after the second Intifada erupted in September 2000, Israel began establishing a new regime of checkpoints crisscrossing a large part of the West Bank (Handel 2011). These checkpoints were erected not only to monitor and control the entry of Palestinians into pre-1967-border Israel, but also in order to monitor/control the movement of Palestinians between Palestinian villages, towns, and cities within the West Bank. Both the army and the border police were put in charge of deploying and running these checkpoints, which placed young enlisted soldiers in charge of carrying out the actual monitoring of the Palestinian population. In accordance with the racist purpose of facilitating the occupation, Jews - both settlers in the OPT and nonsettlers-were exempt from inspection at these checkpoints and thus from any control of movement.

The checkpoints themselves have evolved significantly over the years. They began as no more than roadblocks ("a block, a few sand bags, with a soldier behind them," as described by Barag 2017) and grew into large-scale constructed open-air checkpoints, whose physical design serves the surveillance demands of Israeli security agencies and the desire to run the checkpoint in an orderly fashion. The checkpoints also reinforce the perception that all Palestinians pose a security threat (including to the checkpoint personnel) and create a number of human rights issues that derive from the problems that arise when masses of people are made to wait for a long time in order to pass. Beyond the checkpoints themselves, a variety of steps have been taken to prevent Palestinians from bypassing the checkpoints (Braverman 2012), such as the construction of the West Bank barrier and the establishment of a strict permit system.

Once the checkpoints had transformed into Israel's main surveillance and movement restriction tool in the OPT, they required the investment of a significant degree of resources for their operation. Beyond the capital drain of constructing and maintaining permanent checkpoints that "service" the entire West Bank Palestinian population, there was a need for trained personnel and for competent management that would operate these checkpoints 
efficiently. The fact that these facilities enable unwanted control over a large ethnic/national group has made them a potential target for attack, which further increases their resource drain on state agencies. The well-documented chronic unwillingness of the Israeli government to allocate the required resources (State Comptroller of Israel 2011) has exacerbated the stress on the checkpoints, increased the crossing time, and produced further human rights violations.

From the perspective of ordinary Palestinians, avoiding the checkpoints is not motivated primarily by a desire to avoid the imposed transparency. It is more about preventing the significant time loss and discomfort that these checkpoints entail, and their tendency to arbitrarily prevent free movement. Waiting in long lines, sometimes for more than an hour or two, with other people who also want to make it through promptly, produces major discomfort, and sometimes even triggers pushing, fainting, and incidents of violence. Movement is denied for any number of reasons, most of them unknown to the person passing through until s/he is actually refused passage. ${ }^{1}$ Beyond the "lawful reasons" (if we can call them that) for denying movement, the fact that the soldiers/border police tasked with running these checkpoints have little relevant training, are overworked, and work under harsh conditions, means that many denials are made for unlawful reasons or due to ignorance of the rules (Hallward 2008; Mansbach 2009). This adds still more arbitrariness to a process that is arbitrary to begin with.

Despite the fact that these checkpoints immediately became loci of massive human rights violations, and despite Israel's and Palestine's small size (which makes the checkpoints more accessible for observation), what went on in them remained largely unknown to both the Israeli public and the international community (Barag 2019). This opaqueness granted the Israeli security forces virtually free rein to operate the checkpoints as they pleased.

\section{Second move: monitoring checkpoints by human rights NGOs}

The reaction of human rights NGOs to the creation of this checkpoint regime was to impose transparency on the government agencies managing and operating it. These surveillance efforts in the name of Palestinian human rights were part of well-established practices of empowering surveillance whereby NGOs monitor Israeli agencies operating in the OPT (Duke 2019). These practices date back to the end of the 1980s and were spearheaded by JewishIsraeli NGOs, which, due to their inclusion in the dominant community, were (and still are) in a special position to gain the cooperation of Israeli agencies.

With the new checkpoint regime in place, some existing NGOs turned their attention to these checkpoints, while in 2001 one new organization was created specifically with the purpose of monitoring them, appropriately named Machsom (checkpoint in Hebrew) Watch. This organization's activists (all volunteers) carry out monitoring at the checkpoints. This allows both 
the unmediated observation of what goes on in the checkpoints in real time, and affords the opportunity to intervene in the actions of soldiers/officers operating the checkpoints in order to prevent human rights violations as they unfold (Hallward 2008; Kotef and Amir 2007; Mansbach 2007). Their constant presence at the varied West Bank checkpoints and their intense contact with officers in the Israeli army enabled Machsom Watch activists to pressure the army into making changes in both the checkpoints' procedures and their physical design (Barag 2017; Helman 2015; Hirschfield 2007; Kotef and Amir 2007; Mansbach 2007).

At its peak, Machsom Watch numbered hundreds of activists across Israel, distributed among several different geographical regions, with most of them engaged in checkpoint observation in the West Bank on a weekly basis (Bar 2017; Barag 2017; Braverman 2012; Hallward 2008; Mansbach 2007). This created a situation in which large checkpoints would be monitored at least once a day, while smaller checkpoints would be examined at least once a week. In this way they were able to put in place a mechanism of constant monitoring and intervention, and established themselves as the third major party to the interaction between Palestinians and Israeli security forces at these checkpoints.

Machsom Watch's primary focus on checkpoints and their unmediated contact in "the field" allowed them to gain a great deal of perspective, information, and know-how regarding these checkpoints, their effects on the Palestinians, the military rules that are supposed to govern them, and the de facto arbitrariness that actually governs them most of the time (Braverman 2012). Although the Watch members mostly lacked any identifying features, their constant presence was hard to miss, and it seems most checkpoint operators recognized them and saw them as something between a burden and a full-fledged enemy (Bar 2017; Kutz-Flamenbaum 2016). Machsom Watch's huge database of checkpoint reports is full of descriptions of confrontational encounters with checkpoint operators. The database is also indicative of the intensive contact such monitoring entails between the activists and the higher-ranking officers, who were routinely asked to intervene in either structural/procedural issues, or in individual cases, when common ground with the checkpoint soldier/officer could not be reached.

It is thus of no surprise that those operating the checkpoints tried to undermine the activists' monitoring in a variety of ways. For instance, they often told the activists to move to another spot, away from where the soldier/officer stood (Bar 2017; Kutz-Flamenbaum 2016). In extreme cases, they tried to declare the checkpoint and its surroundings "a closed military area" which, if accepted, would have required the activists to vacate the area and cease the monitoring. However, Machsom Watch activists fiercely resisted these latter practices by being well informed about what is required by law to declare a closed military zone, and by refusing to give merit to any verbal declaration that did not adhere to such requirements (Mansbach 2007, 2009). Still, 
attempts to stop the monitoring of checkpoint operators most probably only increased the frustration of the soldiers/officers, whose transgressions continued to be monitored by a group of civilians and were sometimes reported to their superiors.

\section{Third move: new hi-tech indoor checkpoints}

The next move was made by the Israeli government, and specifically by the Israeli agencies managing and running the checkpoints, and it marked a radical change to a portion of the checkpoints - those that were in proximity to either the pre-1967 border or to the borders of Larger Jerusalem. These checkpoints were to become "terminals" resembling airports or "normal" land border crossings. Among other things, this shift would entail making these checkpoints more permanent structures, shifting their operation from being run by soldiers/officers to specialized civilian personnel, and replacing much of the close-proximity personal monitoring functions of the checkpoint with less-conspicuous surveillance technologies.

The new indoor checkpoints were part of a greater scheme that also included the construction of the Separation Wall, which circles the West Bank. This project, devised by the Israeli government around 2002-2003, would create a situation in which all Palestinian movement into pre-1967 Israel can only be done via the new indoor checkpoints (State Comptroller of Israel 2011). While in line with contemporary world trends to reduce uncontrolled movement of "undesirables" to a minimum and to privatize border work (Bigo 2006; Walsh 2010), Israel's approach also diverges from this trend in that this border work has not been made more mobile, more ad hoc, or less formalized like in other places (e.g. Andreas and Snyder 2000; Bigo and Guild 2005), but quite the reverse; it is much more permanent and formal than before (Braverman 2011).

The shift to indoor checkpoints took a long time to realize, was implemented unevenly among the different "terminals," and was riddled with errors. In some ways, this project is still ongoing since the full hi-tech vision of a shipshape terminal was realized only in two "model" crossings (Qalandiya and Checkpoint 300), while the remaining crossings still have a way to go. What became common to all the terminals was the much greater transparency they enforced on Palestinians passing through them. The gradual introduction of database links, magnetic ID cards, and biometrics (e.g. fingerprint reading) allows for much closer monitoring of each Palestinian passing through (Kotef and Amir 2007). Of course, greater transparency spells out greater and more sophisticated movement restrictions.

With regard to the issue of checkpoint operation transparency, what was most critical in this transformation was the shift indoors (Braverman 2012; Mansbach 2009). This meant that the checkpoint would no longer be open to the NGOs' inspection, direct monitoring, and intervention (Afek 2019; 
Konforty 2017; Kotef and Amir 2007). While at the open-air checkpoints activists could stand outside the fences and still monitor and intervene, the walls of the indoor checkpoints prevent such monitoring. In addition, in the new terminals Palestinians passing through the checkpoint would no longer be able to plea with the checkpoint operators, to reason with them, or to alert them of any problem they encountered, because the operators are mostly hidden behind walls, heavy-duty glass windows, and CCTV (Braverman 2012; Kotef and Amir 2007; Mansbach 2009; Rijke and Minca 2019). In this new system, the limited transparency that was previously forced on the operators of the checkpoint is now largely lost.

Was this an intended consequence or maybe a coincidence or an oversight on the part of the decision makers? There are several indications that this was a sought-after consequence, even if not an explicit one. First, these terminals were developed from scratch. They were not just another patch on the existing structures, such as the many upgrades that open-air checkpoints underwent, but an entirely new structure designed purposely several years after the checkpoint regime was put in place. Thus, these structures were deliberately designed to lack any outward-facing windows and avoided any inclusion of a physical or virtual viewing gallery, which would have allowed human rights activists and reporters to view the checkpoint processes. Similarly, the lack of any opportunity for feedback from the Palestinians crossing the checkpoint was a desired consequence. While the operators use the specially installed loudspeakers to communicate with the Palestinians, there is "no technology installed to hear possible responses, which explains why Palestinians have to shout or communicate via signs" (Rijke and Minca 2019).

This intentional lack of transparency and one-sidedness of interaction is further reinforced by the reasons given for this transition to indoor terminals. While there are several motivations for this transformation, what consistently appeared at the top of the list of explicit goals was "reducing friction" (Davidov 2014; State Comptroller of Israel 2011). That is, reducing instances in which the operators come into direct contact with the Palestinian population and, I would add, with the human rights activists who monitor and intervene on their behalf. Indeed, as discussed above, both types of interaction tend to produce conflicts and are perceived as a burden by the checkpoint operators and to some extent by the higher army ranks. Therefore, the new type of checkpoint tries to achieve architecturally what in the past soldiers and field commanders tried to achieve unlawfully - to close off the checkpoints to any form of outside monitoring.

This closing off also suited the interests of those higher up the pecking order. Both the security forces' top ranks and the Israeli political leadership of the last decade and a half seem to be invested in upholding the checkpoint regime, as it is highly consensual among the Jewish population. Naturally, bad press, locally and internationally, runs the risk of putting pressure on the Israeli government and ultimately endangering the legitimacy of the 
checkpoint regime (Davidov 2014). Hiding what is taking place in these checkpoints from sight and oversight thus serves to avoid negative reactions (Barag 2019; Handel and Dayan 2017). A good indication that this is in fact the thinking is that the two model terminals - the ones that actually resemble an airport-are the ones most exposed to the international community (Hass 2019).

Did this shift to terminals achieve the goals of reducing the operators' transparency? It seems it mostly did. To this day, in all but the two model indoor checkpoints Machsom Watch activists are not allowed to monitor, not even by passing through them as a Palestinian crosser does, while the two terminals that do allow activists to enter are limited to this single crossing-through procedure. Sporadic supervised visits to the checkpoints were organized following requests from activists/reporters, but it seems each time they occurred, the checkpoint was closed off for crossing (Afek 2019; Maor 2019), which meant the visitors did not witness real-world conditions. Machsom Watch activists did not cease their monitoring activities because of this shift, but have had to rely on the feedback of Palestinians exiting the checkpoints in order to understand what is going on within them. They still inspect each checkpoint's facilities and surroundings (Afek 2019; Bar 2019; Barag 2019), yet the bulk of their monitoring and their intervention disappeared with the move indoors.

\section{Case study B: the dynamics around Palestinian human rights NGOs ${ }^{2}$}

\section{First move: monitoring human rights violations}

As mentioned above, Israeli NGOs have been monitoring Israeli agencies and settler actions for human rights violations for almost three decades. There are currently at least three dozen of these monitoring bodies that engage in some sort of empowering surveillance (Aggestam and Strömbom 2013; Avni 2006; Duke 2019; Fleischmann 2016; Helman 2015; Miretski and Bachmann 2014). That is, they are imposing transparency on government agencies in the name of universal human rights norms. The monitoring is done by a variety of methods such as direct observation, testimony collection, evidence collection, taking affidavits, gathering pictures and video data, making judicial inquiries, making formal and informal information requests, and more.

The collected data is used to monitor violations of human rights by a variety of government agencies and by right-wing social groups that either operate in the OPT or have a role in perpetuating the occupation. NGO proficiency in collecting data, processing it, and disseminating information arising from it has rendered them the primary source of information regarding the OPT for international forums, journalists, scholars, foreign government agencies, and even Israeli government agencies (Barag 2017; Braverman 2012; KutzFlamenbaum 2016; Miretski and Bachmann 2014). Indeed, the reliance of 
government agencies on the information these NGOs gather and analyze is a testament to the quality of work that they do.

These organizations are thus committed both to stopping human rights violations in the short run and to ending the decades-long Israeli occupation of the Palestinian territories. Yet, what these NGOs have found over the course of their activity is that merely putting the information on the web, available for all the world to see, is not enough. They have also learned that a large majority of the Israeli public does not want to hear about these violations or the occupation in general (Aggestam and Strömbom 2013; Avni 2006; Desai 2015; Fleischmann 2016; Helman 2015), and that in the international arena Palestinian suffering "competes" for attention with many other types of suffering by different groups. This has pushed the organizations to be much more active in their dissemination of information and to dynamically seek an audience. Thus, beyond responding to queries that seek information, some of these NGOs often approach relevant forums that might see value in such information, produce pressure on the Israeli government, and eventually affect decision-making processes.

Nevertheless, despite all the dedication and creativity that Israeli human rights NGOs invest in their endeavor, their overall success is limited (Aggestam and Strömbom 2013; Fleischmann 2016; Kutz-Flamenbaum 2016; Miretski and Bachmann 2014). The occupation in general seems to be deepening with time, and the goal of either nullifying or eroding it has clearly not been realized. Moreover, the much more modest aspiration to put an end to systematic violations of human rights has had a very limited effect.

\section{Second move: attack from the right-wing}

It is precisely the role Israeli NGOs play in disseminating information about human rights violations perpetuated against Palestinians that causes a huge backlash against them within Israeli society (Avni 2006; Handel and Dayan 2017). The Israeli right-wing, which enjoys widespread support among Jews in Israel, has recognized that by imposing transparency upon government agencies, and by communicating the mass violation of human rights to publics and organizations abroad, these NGOs are exposing Israel to pressure to change its policies and end the occupation. The right-wing has recognized that this type of transparency jeopardizes the constant gains it enjoys in terms of solidifying and normalizing the occupation and that it should enlist its political power and its control of the Israeli government in order to terminate this transparency.

The method the Israeli right-wing has chosen involves a combination of direct attacks by individuals, groups, and organizations, and indirect attacks using legislative and administrative power (Handel and Dayan 2017). Israel's right-wing control over state power has been used in several ways in order to weaken these NGOs. For instance, taxation policies were altered in order to 
make donations to human rights NGOs less attractive and ultimately diminish their funding (Aggestam and Strömbom 2013; Policy Working Group 2018; Sucharov 2016). Legislative steps have also been taken, allegedly in the name of greater transparency, to force these specific NGOs to disclose the sources of their funding (Gild-Hayo 2018) in order to reveal that a significant portion of donations to Israeli human rights NGOs originates from foreign entities.

Complementing these legislative transparency steps were the steps taken by private right-wing individuals, groups, and organizations aimed at delegitimizing NGOs. Such steps included several media campaigns that focused on the fact that much of their funding comes from abroad, and thus painted them as traitors. Among them was a propaganda video titled "The Moles," produced by Im Tirzu (a far-right Israeli organization), which suggests a link between terrorist attacks against Israelis and four figures from four Israeli human rights NGOs. The video claims that these activists and the organizations they are affiliated with work for foreign interests opposing Israel. ${ }^{3}$ Tapping into a well-known distrust of Israeli Jews toward foreign governments/bodies, this video attempts to enrage the public against these organizations and provoke retaliation against them.

Another use of transparency by the Israeli right-wing is evident in the heavily funded project "NGO Monitor." This website holds a detailed database of all the human rights-related NGOs that operate in Israel/Palestine. On its homepage, the organization describes its mission as follows: "we work to ensure that decision makers and civil society operate in accordance with the principles of accountability, transparency, and universal human rights" (NGO Monitor 2019). Although not unprecedented (e.g. Kutz-Flamenbaum 2016; Perugini and Gordon 2015), this is in fact one of the most blatant attempts to use Israeli human rights NGOs' rhetoric and methods against them.

\section{Third move: minimal transparency}

The effects of the sophisticated right-wing moves against the Israeli human rights NGOs have been nontrivial but still limited. The ultimate goal of disabling these organizations or intimidating them into docility has not been attained. Indeed, the top management of these organizations explicitly says that these campaigns have not changed their work procedure in any significant way (Gvaryahu 2019; Montell 2019).

That said, it is evident that these attacks have posed a challenge to these organizations and hijacked some of their time, attention, and energy. Repeated threats of physical assault against activists, sometimes with indications that these activists were being followed/surveilled, and a handful of actual assaults that took place, have rattled NGO activists (Gvaryahu 2019). Activists from the more well-known human rights NGOs, for instance, try to keep their affiliation somewhat secret (Doe 2017; Smith 2017). The NGOs themselves have in some instances needed to coordinate security arrangements (Gvaryahu 
2019; Montell 2019). Beyond the threat of vigilantism from militant rightwing activists, there is a threat of verbal attacks, refusal of service, or workrelated reprisals that seems to come from the general Jewish public, which shows strong and sometimes active support for the fight against internal and external "enemies" (Dishy 2017; Kuntsman and Stein 2015). Another type of attack that these organizations, especially the most visible, face is cyberattacks, requiring some NGOs to defend themselves accordingly (Yellin 2017).

These NGOs have needed to adapt institutionally, since they are now legally required to disclose certain facts regarding their funding. Yet these legal obligations have not pushed them to more substantial transparency, but rather to adhere to the letter of the law. Among other things, they are now required to publish a quarterly list of foreign donors, to specify on their website and in mail correspondence if they are mostly funded by foreign entities, and when appearing before the Israeli Parliament, to inform the committee chair of the same. An examination of these NGOs' websites shows that they adhere to these provisions, and sometimes do so under a "Transparency" section. However, that same examination (conducted twice in 2018 and 2019) showed that they did not go beyond what is required by law in any significant measure, although hypothetically this opportunity could have been used to disclose further information. In fact, there are good indications that the combined attacks have shifted these organizations slightly away from transparency and toward opaqueness in their dealings with elements outside the organization. This was alluded to by several activists whom I interviewed (e.g. Doe 2017), and also experienced by me directly when trying to secure interviews. I often found myself denied access and asked to provide ample assurances regarding my aims before and during interviews.

It is precisely the sophisticated use of imposed transparency on the part of the right-wing that has provoked this modest but apparent retreat from transparency by such organizations. Among the tactics that were used at least in one conspicuous case - that of the NGO Breaking the Silence-was the organization's infiltration by several right-wing activists in order to gather information that would present the organization in a negative light and expose it to the public (Gvaryahu 2019). Fears of such forms of information-seeking have provoked heightened suspicion toward unknown outsiders and a much more robust vetting process of would-be activists.

When asked to explain what makes both the governmental and nongovernmental efforts to impose transparency on Israeli human rights NGOs instances of "bad faith," interviewees point to their one-sided applicability. NGO Monitor only directs its probes to left-wing organizations, is itself not transparent, and heavily decontextualizes the information it gathers (Policy Working Group 2018; Sfard 2017). The legislation that was passed forcing transparency on these NGOs was carefully worded in order to apply mainly to left-wing human rights NGOs, and not across the board. Even when it 
did apply, right-wing NGOs were de facto exempt from it (Bendet 2015; Gvaryahu 2019; Montell 2019). Thus, since these attempts of forced transparency are not universal, they are perceived as illegitimate and disingenuous.

\section{Conclusion}

After analyzing the two OPT case studies, what becomes obvious is that imposed transparency is amply used to achieve strategic political goals. New forms of disclosure are constantly being invented and imposed on a targeted party in order to achieve "security," restriction of movement, protection of human rights, the end of the occupation, and other goals. None of the described transparency moves were universally applied. The checkpoints only target Palestinians with their imposed transparency. Jewish settlers, although implicated in a variety of crimes against Palestinians, are not inspected. Similarly, Machsom Watch activists target the checkpoints of the West Bank for monitoring. They do not monitor what other security personnel do in the OPT, nor the occasional crimes carried out against soldiers/police officers. None of the parties asked for consent, and no consent has been given by the targets of imposed transparency. Moreover, most of the transparency is achieved by monitoring/surveillance, and there is very little self-disclosure in the process. Hence, the presented cases lie almost squarely within the imposed transparency archetype (see Table 4.1) and are a good representation of its dynamics.

As the empirical analysis shows, imposed transparency is not something that targeted organizations and individuals seem to come to terms with. Resistance/evasion is strong and both individuals (e.g. soldiers) and organizations (e.g. NGOs) are constantly seeking ways to shake off the monitoring that is imposed on them. Translated into the study of surveillance, the above observed dynamics have pessimistic prospects for the viability of Bentham's and Foucault's idea of internalization of the watching eye in situations of constant imposed monitoring. In fact, the end result is the Foucauldian panopticon effect in reverse-instead of self-regulation, these organizations and individuals opt for regression to opaqueness. This insight may serve as a warning sign for those who overestimate the power of surveillance and of imposed transparency - these tools may achieve an immediate desired goal, but in cases when they truly expose the targets to negative effects, they will probably be neither internalized nor accepted.

Cycles of imposed and counter-imposed transparency seem to come with negative side effects. Among them are the personalization of animosity and the erosion of the concept of transparency. Imposed transparency appears to personalize animosity by connecting what targets perceive as a negative outcome with the entity that initiated it. The term transparency, for its part, sheds all of its positive connotations in this process and becomes hollow and 
strictly utilitarian. Most importantly, imposed transparency does not serve as a gateway to voluntary transparency, instead breeding even greater opacity.

That said, we have to acknowledge the sharp asymmetry in power between the different parties in these cycles of imposed transparency. As the empirical examination shows, this asymmetry means that both applying imposed transparency and coping with its imposition as a target are much more effective for the powerful side than for the weaker side. Powerful organizations, such as the army, can establish massive operations of imposed transparency and can rely on their heavy state support to avoid being the target of imposed transparency. Weak groups/organizations can apply imposed transparency, but with great investment of effort and at significant personal cost. Their ability to avoid being targeted also requires a disproportionate investment of energy and has limited results. That said, although imposed transparency favors the strong, it is often the only recourse of the weak. In our case, this asymmetry, which is part of the colonial settings in the Middle East, means that the NGOs' imposed transparency only succeeds in stopping the most egregious violations of Palestinian human rights, and that the occupation is neither eliminated nor curbed.

\section{Notes}

1 It is of course paradoxical that the process of demanding transparency from Palestinians is itself starkly untransparent.

2 This section refers to all Israeli NGOs dealing with Palestinian human rights, not just those dealing with checkpoints.

3 The video is available here: https://youtu.be/02u_J2C-Lso.

\section{References}

Abu-Laban, Yasmeen. 2014. "Gendering Surveillance Studies." Surveillance \& Society 13(1): 44-56.

Aggestam, Karin, and Lisa Strömbom. 2013. "Disempowerment and Marginalisation of Peace NGOs.” Peacebuilding 1(1): 109-24.

Allen, David S. 2008. "The Trouble with Transparency." Journalism Studies 9(3): 323-40.

Andreas, Peter, and Timothy Snyder, eds. 2000. The Wall Around the West: State Borders and Immigration Controls in North America and Europe. Lanham, MD: Rowman and Littlefield.

Auger, Giselle A. 2014. "Trust Me, Trust Me Not." Journal of Public Relations Research 26(4): 325-43.

Avni, Ronit. 2006. "Mobilizing Hope: Beyond the Shame-Based Model in the IsraeliPalestinian Conflict." American Anthropologist 108(1): 205-14.

Bac, Mehmet. 2001. "Corruption, Connections and Transparency." Public Choice 107(1): 87-96. 
Bannister, Frank, and Regina Connolly. 2011. "The Trouble with Transparency." Policy \& Internet 3(1): 1-30.

Bauhr,Monika, and Marcia Grimes. 2014. "Indignation or Resignation:TheImplications of Transparency for Societal Accountability.” Governance 27(2): 291-320.

Bendet, Shabtai. 2015. "Under the Auspice of the Registrar of Associations: RightWing NGOs Are Evading Disclosing Funding Sources." Walla, December (in Hebrew).

Bertot, John C., Paul T. Jaeger, and Justin M. Grimes. 2010. "Using ICTs to Create a Culture of Transparency." Government Information Quarterly 27(3): 264-71.

Bessire, Dominique. 2005. "Transparency: A Two-Way Mirror?" International Journal of Social Economics 32(5): 424-38.

Bigo, Didier. 2006. "Globalized-in-Security: The Field and the Ban-Opticon." Traces: A Multilingual Journal of Cultural Theory 4: 109-57.

Bigo, Didier, and Elspeth Guild, eds. 2005. Controlling Frontiers: Free Movement into and Within Europe. Hampshire: Ashgate.

Braverman, Irus. 2011. "Civilized Borders: A Study of Israel's New Crossing Administration." Antipode 43(2): 264-95.

Braverman, Irus. 2012. "Checkpoint Watch: Reflections on Israel's Border Administration in the West Bank." Social \& Legal Studies 21: 297-320.

Brucato, Ben. 2015. "The New Transparency: Police Violence in the Context of Ubiquitous Surveillance." Media and Communication 3(3): 39-55.

Davidov, Eldad. 2014. "Not Occupiers, Service Providers." Hamakom Hachi Ham Bagehenom, December (in Hebrew).

Desai, Chandni. 2015. "Shooting Back in the Occupied Territories: An Anti-colonial Participatory Politics." Curriculum Inquiry 45(1):109-28.

Dishy, Aaron. 2017. "Selfies, Sexts, and Squadrons: The Digital Culture of the Israeli Defense Forces." iJournal 2(2). https://theijournal.ca/index.php/ijournal/article/ view/28122.

Drucker, Susan J., and Gary Gumpert. 2007. "Through the Looking Glass: Illusions of Transparency and the Cult of Information." Journal of Management Development 26(5): 493-8.

Dubrofsky, Rachel E., and Shoshana A. Magnet. 2015. "Feminist Surveillance Studies: Critical Interventions." In Feminist Surveillance Studies, edited by Rachel E. Dubrofsky, and Shoshana A. Magnet, 1-17. Durham, NC: Duke University Press.

Duke, Shaul A. 2019. "Database-Driven Empowering Surveillance: Definition and Assessment of Effectiveness." Surveillance \& Society 17(3/4): 499-516.

Fleischmann, Leonie. 2016. "Beyond Paralysis: The Reframing of Israeli Peace Activism since the Second Intifada." Peace \& Change 41(3): 354-85.

Foucault, Michel. (1975) 1991. Discipline and Punish. New York, NY: Vintage Books.

Gild-Hayo, Debbie. 2018. Overview of Anti-Democratic Legislation Advanced by the 20th Knesset. Tel Aviv: The Association for Civil Rights in Israel.

Gilliom, John, and Torin Monahan. 2012. "Everyday Resistance." In Routledge Handbook of Surveillance Studies, edited by Kirstie Ball, Kevin Haggerty, and David Lyon, 405-11. London: Routledge.

Grimmelikhuijsen, Stephan G. 2010. "Transparency of Public DecisionMaking: Towards Trust in Local Government?" Policy \& Internet 2(1): 5-35. 
Grimmelikhuijsen, Stephan G., Gregory Porumbescu, Boram Hong, and Tobin Im. 2013. "The Effect of Transparency on Trust in Government." Public Administration Review 73(4): 575-86.

Hall, Rachel. 2017. "Surveillance and Public Space." In Oxford Research Encyclopedias: Communication,1-17.https://doi.org/10.1093/acrefore/9780190228613. 013.145

Hallward, Maia Carter. 2008. "Negotiating Boundaries, Narrating Checkpoints: The Case of Machsom Watch." Critique: Critical Middle Eastern Studies 17(1): 21-40.

Handel, Ariel. 2011. "Exclusionary Surveillance and Spatial Uncertainty in the Occupied Palestinian Territories." In Surveillance and Control in IsraellPalestine, edited by Elia T. Zureik, David Lyon, and Yasmeen Abu-Laban, 259-75. London: Routledge.

Handel, Ariel, and Hilla Dayan. 2017. "Multilayered Surveillance in Israel/Palestine." Surveillance \& Society 15(3/4): 471-76.

Hass, Amira. 2019. "Renovated Checkpoints for Palestinians Are Nothing but Crumbs of Mercy." Haaretz, December.

Helman, Sara. 2015. "Challenging the Israeli Occupation Through Testimony and Confession.” International Journal of Politics, Culture, and Society 28(4): 377-94.

Hirschfield, Robert. 2007. "The Checkpoint Women of Israel." In These Times, December.

Jackson, Brian A. 2015. Strengthening Trust between Police and the Public in an Era of Increasing Transparency. Santa Monica, CA: RAND Corporation.

Kanagaretnam, Kiridaran, Stuart Mestelman, Khalid S. M. Nainar, and Mohamed Shehata. 2010. "Trust and Reciprocity with Transparency and Repeated Interactions." Journal of Business Research 63(3): 241-7.

Kolstad, Ivar, and Arne Wiig. 2009. "Is Transparency the Key to Reducing Corruption in Resource-Rich Countries?" World Development 37(3): 521-32.

Koskela, Hille. 2012. "'You Shouldn't Wear that Body': The Problematic of Surveillance and Gender." In Routledge Handbook of Surveillance Studies, edited by Kirstie S. Ball, Kevin D. Haggerty, and David Lyon, 49-56. London: Routledge.

Kotef, Hagar, and Merav Amir. 2007. "(En)Gendering Checkpoints: Checkpoint Watch and the Repercussions of Intervention." Signs 32(4): 973-96.

Kuntsman, Adi, and Rebecca L. Stein. 2015. Digital Militarism: Israel's Occupation in the Social Media Age. Palo Alto: Stanford University Press.

Kutz-Flamenbaum, Rachel V. 2016. "The Importance of Micro-Level Effects on Social Movement Outcomes.” Sociological Perspectives 59(2): 441-59.

Lentin, Ronit. 2017. "Race and Surveillance in the Settler Colony." Palgrave Communications 3: 17056.

Lindstedt, Catharina, and Daniel Naurin. 2010. "Transparency Is Not Enough: Making Transparency Effective in Reducing Corruption." International Political Science Review 31(3): 301-22.

Mann, Steve. 2013. "Veillance and Reciprocal Transparency." International Symposium on Technology and Society, Toronto, December.

Mansbach, Daniela. 2007. "Crossing the Borders: The Power of Duality in the Protest of the 'Checkpoint Watch' Movement." Theory and Criticism 31: 77-99 (in Hebrew).

Mansbach, Daniela. 2009. "Normalizing Violence: From Military Checkpoints to 'Terminals' in the Occupied Territories." Journal of Political Power 2(2): 255-73. 
Margetts, Helen. 2011. "The Internet and Transparency." Political Quarterly 82(4): 518-21.

Marsh, Kevin. 2011. "The Illusion of Transparency." Political Quarterly 82(4): 531-5.

Marx, Gary T. 2003. "A Tack in the Shoe: Neutralizing and Resisting the New Surveillance." Journal of Social Issues 59(2): 369-90.

Miretski, Pini P., and Sascha-Dominik V. O. Bachmann. 2014. "The Panopticon of International Law: B'Tselem's Camera Project." Osgoode Hall Law Journal 52(1): 235-62.

Monaghan, Jeffrey. 2013. "Settler Governmentality and Racializing Surveillance in Canada's North-West." Canadian Journal of Sociology 38(4): 487-508.

NGO Monitor. 2019. "NGO Monitor." www.ngo-monitor.org/.

O'Neill, Onora. 2002. A Question of Trust: The BBC Reith Lectures 2002. Cambridge: Cambridge University Press.

Perugini, Nicola, and Neve Gordon. 2015. The Human Right to Dominate. Oxford: Oxford University Press.

Policy Working Group. 2018. NGO Monitor: Shrinking Space. Jerusalem: Policy Working Group.

Rawlins, Brad R. 2008. "Measuring the Relationship Between Organizational Transparency and Employee Trust.” Public Relations Journal 2(2): 1-21.

Rijke, Alexandra, and Claudio Minca. 2019. "Inside Checkpoint 300: Checkpoint Regimes as Spatial Political Technologies in the Occupied Palestinian Territories." Antipode 51(3): 968-88.

Schnackenberg, Andrew K., and Edward C. Tomlinson. 2016. "Organizational Transparency: A New Perspective on Managing Trust." Journal of Management 42(7): 1784-810.

Schnorf, Sebstian, Martin Ortlieb, and Nikhil Sharma. 2014. "Trust, Transparency \& Control in Inferred User Interest Models." Conference on Human Factors in Computing Systems, Toronto, December, 2249-54.

Sfard, Michael. 2017. "After a Decade of Persecution I Decided to Break the Silence and to Answer Gerald Steinberg." Siha Mekomit, December (in Hebrew).

Sperling, Stefan. 2011. "The Politics of Transparency and Surveillance in PostReunification Germany.” Surveillance \& Society 8(4): 396-412.

State Comptroller of Israel. 2011. The 2010 Annual Report 61A. Jerusalem: State Comptroller of Israel (in Hebrew).

Sucharov, Mira. 2016. “Is B’Tselem Right to Quit Playing 'Middle Man' for the IDF?" Forward, December.

Trottier, Daniel, Rashid Gabdulhakov, and Qian Huang. 2020. "Introducing Vigilant Audiences." In Introducing Vigilant Audiences, edited by D. Trottier, R. Gabdulhakov, and Q. Huang, 1-23. Cambridge: OpenBook Publishers.

Walsh, James P. 2010. "From Border Control to Border Care: The Political and Ethical Potential of Surveillance." Surveillance \& Society 8(2): 113-30.

Wilson, Dean J. 2012. "Counter-Surveillance, Protest and Policing." Plymouth Law and Criminal Justice Review 4: 33-42.

Wilson Dean J., and Tanya Serisier. 2010. "Video Activism and the Ambiguities of Counter-Surveillance.” Surveillance \& Society 8(2): 166-80.

Young, Sarah. 2020. "More Eyes on Crime?: The Rhetoric of Mediated Mugshots." In Introducing Vigilant Audiences, edited by D. Trottier, R. Gabdulhakov, and Q. Huang, 307-30. Cambridge: OpenBook Publishers. 
Zureik, Elia T. 2001. "Constructing Palestine Through Surveillance Practices.” British Journal of Middle Eastern Studies 28(2): 205-27.

Zureik, Elia T. 2011. "Colonialism Surveillance, and Population Control: Israel/ Palestine." In Surveillance and Control in Israel/Palestine, edited by Elia T. Zureik, David Lyon, and Yasmeen Abu-Laban, 3-46. London: Routledge.

Zureik, Elia T. 2016. Israel's Colonial Project in Palestine: Brutal Pursuit. London: Routledge.

\section{Interviews}

Afek, Rachel (activist, Machsom Watch), telephone, September 12, 2019.

Bar, Shuli (activist, Machsom Watch), telephone, November 16, 2017 and September 12, 2019.

Barag, Hanna (activist, Machsom Watch and Yesh Din), in person, Jerusalem, November 14, 2017 and by telephone, September 9, 2019.

Doe, John (former B'Tselem employee, pseudonym), in person, Tel-Aviv, November 28, 2017.

Gvaryahu, Avner (director of Breaking the Silence), telephone, September 23, 2019.

Konforty, Aviva (activist, Machsom Watch), telephone, November 22, 2017.

Maor, Idit (activist, Machsom Watch), telephone, September 16, 2019.

Montell, Jessica (director of HaMoked), telephone, September 12, 2019.

Smith, John (former B'Tselem employee, pseudonym), in person, Tel-Aviv, November 15, 2017.

Yellin, Roy (director of Public Outreach at B'Tselem), telephone, December 19, 2017. 